\title{
Comparison of pregnant women from public and private health care: a psychological approach
}

Juliana Fernandes Filgueiras Meireles 1

https://orcid.org/0000-0001-8396-6449

Clara Mockdece Neves 2

https://orcid.org/0000-0002-5240-6710

Marcella Fernandes Paticcié Nacif 3

https://orcid.org/0000-0002-3053-0593

Pedro Henrique Berbert de Carvalho 4

https://orcid.org/0000-0002-4918-5080

Maria Elisa Caputo Ferreira 5

https://orcid.org/0000-0002-3294-7560

1-5 Universidade Federal de Juiz de Fora. Rua José Lourenço Kelmer s.n. Martelos. Juiz de Fora, MG, Brasil. CEP: 36.036-330. E-mail: eujuly90@hotmail.com

\begin{abstract}
Objectives: to compare sociodemographic, anthropometric and psychological factors in pregnant women receiving public and private health care, as well as verify the influence of eating attitudes, depressive symptoms, self-esteem and anxiety on body attitudes in both sectors.

Methods: this study included 386 pregnant women aged 18-46 (mean of $29.32 \pm 6.04$ years). Instruments were applied to evaluate body attitudes, eating attitudes, depressive symptoms, self-esteem and anxiety. Anthropometric and obstetric data were collected. Descriptive, comparative and correlational analyses were performed.

Results: troubled sociodemographic characteristics, negative body attitudes, inappropriate eating attitudes, depressive symptoms, low self-esteem, and high levels of trait and state anxiety were significantly higher among participants receiving public health care $(p<0.05)$. Eating attitudes and self-esteem directly influenced the body attitudes of those receiving public health care ( $R^{2}$ adjusted $\left.=0.336, p<0.001\right)$ and private health care $\left(R^{2}\right.$ adjusted $=0.324, p<0.001)$.

Conclusions: it was concluded that the sociodemographic, anthropometric, and psychological factors were more worrying in pregnant women receiving care in the public sector when compared to those of the private sector.

Key words Body image, Pregnancy, Mental health, Public health
\end{abstract}

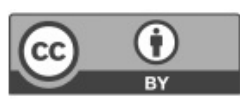




\section{Introduction}

Pregnancy is considered a period of high emotional stress, for it occurs while women undergo social, physical and psychological changes. ${ }^{1-3}$ Body image, which is the mental representation of the body, is present in al of these modifications, since its current definitions include emotions, desires and social interaction. ${ }^{4}$ According to a few authors, the feelings, beliefs, thoughts and behaviors related to the body may undergo modifications during pregnancy. $1-3$

In the theoretical model proposed by Thompson et al. 5 for the study and development of body image, the authors pointed out the influence of sociocultural variables in this construct. As a result, Kamysheva et al. 6 proposed a specific model for pregnant women, which verified the influence of self-esteem, depression and Body Mass Index (BMI) on the feelings toward their bodies. Therefore, current investigations have been trying to identify the relations between sociodemographic, anthropometric and psychological variables and the body image of pregnant women.7-10

Therefore, the professionals who deal directly with this public have to be aware of intervening factors on body image, since they can impact negatively on the mothers' and children's health. 1-3,10 It is possible to mention the following adverse consequences: prenatal and postnatal depression, placental abruption, less maternal-fetal attachment, early breastfeeding interruption, clinical and obstetric complications for the mother, prematurity, and newborns with low weight .10-13

Recent study showed that the quality of health services may vary between public and private sectors, 14 including those services offered to pregnant women. ${ }^{15-17}$ These differences may appear in many aspects, such as higher number of medical consultations and ultrasound scans pregnant women of the private sector have access to, higher neonatal mortality of public services, and also the different sociodemographic traits that both groups present. ${ }^{15,16}$ Furthermore, there is a lack of studies that take into account the possible psychological differences between pregnant women from both public and private sectors. Getting to know these peculiarities may enable better suitability during consultations and care for pregnant women, since in both environments these patients may present different traits that, as a result, require different actions.

The objective of this study was to compare sociodemographic, anthropometric and psycholo- gical factors in pregnant women receiving care in the public and private health sectors, as well as verify the influence of eating attitudes, depressive symptoms, self-esteem and anxiety in the body attitude of the evaluated sample in both sectors. In this research, it was hypothesized that the biopsychosocial attributes would be different among pregnant women in private and public health sectors.

\section{Methods}

This investigation is cross-sectional, with a quantitative, descriptive and correlational approach. 18 This research had the approval of the Committee for Ethics in Research in Humans of the Federal University of Juiz de Fora (Comitê de Ética $e$ Pesquisa em Seres Humanos da Universidade Federal de Juiz de Fora [UFJF]), registration number 14406413.0.0000.5147, approval number 337.124. All the volunteers signed an Informed Consent Form (Termo de Consentimento Livre e Esclarecido [TCLE]), and data collection happened in the city of Juiz de Fora, state of Minas Gerais.

A sample calculation was performed taking into account the number of adult pregnant women in the city of Juiz de Fora (according to official information from the city's Secretary of Health), with prevalence of $50 \%$ of negative body image, $195 \%$ confidence interval and a sampling error of $5 \%$, totalizing a minimum sample size of 361 pregnant women. The sample included pregnant women over 18 years old in all gestational ages who were attending prenatal medical consultations both in public and private health sectors in Juiz de Fora. They all agreed to participate in this investigation voluntarily. Those who had any incomplete information were excluded. In order to evaluate their body attitude (attractiveness, disparagement, feeling fat, salience, perception of lower body fatness, strength and fitness), pregnant women answered the Body Attitudes Questionnaire (BAQ), validated for the Brazilian female adult population by Scagliusi et al. ${ }^{19}$ This instrument has 44 items, on a Likert scale (from one to five), being the total calculated by the sum of the answers, which can vary from 44 to 220 points. The higher the score, the higher the negative feelings toward the evaluated body attitudes. The internal consistency of the sample was calculated through Cronbach's alpha $(\alpha)$ and it has been considered adequate $(\alpha=0.84)$.

In order to determine inappropriate eating attitudes, the Eating Attitudes Test - 26 (EAT-26), validated for Brazilian adults by Nunes et al. 20 was used. This questionnaire is comprised of 26 questions, answered on a Likert scale (from Always, that cor- 
responds to 3 points, to Never, which corresponds to $0)$. The total score is calculated by the sum of all items, which can vary from 0 to 78 points. The higher the score, the higher the indication of inappropriate eating attitudes. For the sample of this study, $\alpha$ was equal to 0.8 and, as a result, considered appropriate.

To investigate the depressive symptoms of the population, the Beck Depression Inventory (BDI) was applied. Its validation in Brazil was conducted by Gorenstein and Andrade. ${ }^{21}$ This is an instrument with 21 items and 4 response options, from 0 to 3 points. The total score is obtained by counting each evaluated item, which can vary from 0 to 63 points. The higher the score, the higher the indication of depression. For this sample, the instrument presented good internal consistency $(\alpha=0.89)$.

Additionally, in order to evaluate self-esteem, the Rosenberg Self-Esteem Scale (RSS) was employed, validated for Brazilian adults by Dini et al.22 The scale is comprised of 10 items with four response options (from 0 to 3 points), on a Likert type and total score that can vary from 0 to 30 points. The higher the score, the higher the level of self-esteem of the pregnant woman. The analysis of its internal consistency for the evaluated pregnant women showed a Cronbach's alpha of 0.85 .

In order to investigate the level of trait and state anxiety, the short version of the Brazilian State-Trait Anxiety Inventory (STAI) was used. The validation study for the Brazilian population was developed by Fioravanti-Bastos et al.23 This instrument has two different scales: part one (state anxiety) and part two (trait anxiety). Both of them are indicated on a fourpoint Likert scale. The final score can vary from 12 to 48 in this questionnaire. Higher scores indicate higher levels of anxiety. The internal consistency for this sample was $\alpha=0.74$.

The socioeconomic status of pregnant women was evaluated by the Brazilian Economic Classification Criteria (Critério de Classificação Econômica Brasil [CCEB]), developed by Brazilian Association of Market Research Companies (Associação Brasileira de Empresas de Pesquisa [CCEB]).24 This instrument differentiates the population by collecting household information such as possession and quantity of home comfort products and level of schooling of the householder. Scores are distributed according to each attribute and, after being totaled, scores can vary from 0 to 46 . The final scores are organized into levels, from A1 to E. In this research, they were classified into: A - from 46 to 35 points; B - from 34 to 23; C - from 22 to 14; D and E - from 13 to 0.24
In order to obtain the sociodemographic data, a questionnaire was applied with direct questions concerning age, level of schooling, marital status, number of children, relationship with the father of the child, family support, whether the pregnancy was planned or not, and the possibility or not of a miscarriage.

Finally, anthropometric (body mass and height) and obstetric (gestational age in weeks) data were obtained through the pregnant women's medical records, which were filled in by the doctor in charge of the patient. The BMI was obtained through the body mass divided by the square of the body height $\left(\mathrm{kg} / \mathrm{m}^{2}\right)$, which was controlled through regression analysis, since previous studies had demonstrated its influence on body attitudes.6,7,13

At the beginning, contact was made with 10 obstetricians that operate privately (private offices or health centers) and publicly (basic health clinics [Unidades Básicas de Saúde] or hospitals) in different neighborhoods in Juiz de Fora/Minas Gerais. The doctors were instructed about the objectives and methods of this study. They all agreed to conduct this study in their offices and therefore informed the researchers about the best days and times for data collection according to their schedule. While waiting for their consultation, the pregnant women were invited to participate voluntarily in a study in the waiting room. They received a verbal explanation about the research, signed the Informed Consent Form, and answered the questionnaires individually, with no time limit. Finally, their updated anthropometric and obstetric data were obtained after their consultation through the medical record filed by the responsible physician.

The internal consistency of each instrument for this study was analyzed by calculating the Cronbach's alpha. Values above 0.70 were considered adequate. ${ }^{25}$ The Kolmogorov-Smirnov test was conducted and the normal distribution of data was confirmed, which justifies the usage of these parametric tests. For the categorical variables, frequency (absolute and relative) was analyzed by sector. The Pearson's chi-squared test was conducted for a variable in order to compare the categorical variables according to the health sectors (public or private) in which the prenatal tests were performed. Fisher's exact test was applied when necessary. The analysis could not be carried out when one of the cells represented a frequency equal to zero. For the remaining variables, measures of central tendency and dispersion (standard deviation) were applied for both sectors. The Student's t-test was used to compare the numerical variables according to the 
health sector. For all the comparative analysis, the size of the effect was evaluated, determined by the Cohen's D. ${ }^{26}$ Effect sizes with lower values than 0.5, between 0.5 and 0.79 , or greater than or equal to 8 were considered small, medium, and large, respectively. 26

Furthermore, the Pearson correlation coefficient was used to verify correlations among the evaluated parameters (BAQ, EAT-26, BDI, RSS, STAI-trait and STAI-state) for each of the health sectors. Finally, in order to verify the predictive expression of each variable on the BAQ, two models of multiple linear regression (forward selection) were performed, one for each health sector. The order of insertion of the variables on this analysis took into account the strength of the correlation of each of them with the BAQ. It is important to mention that the multicollinearity among the variables was tested and it revealed the absence of interference among the variables. Therefore, all the variables related to the body attitudes of pregnant women were included in the regression model. The size of the effect was also calculated in this analysis. 26

For the statistical analysis, the software SPSS 19.0 was used, and in all cases, the significance level was $p<0.05$.

\section{Results}

In this study 417 pregnant women participated. However, 31 did not fill in the questionnaires completely and were excluded. Consequently, the final sample had 386 pregnant women between 18 and 46 years old, out of which 198 were from the public sector $(51.3 \%)$ and $188(48.7 \%)$ from the private. Table 1 presents the sociodemographic attributes of the sample in the different health sectors, as well as the results of the comparison

Table 1

Comparative and descriptive analysis of the sociodemographic variables of pregnant women of the public and private sectors.

\begin{tabular}{|c|c|c|c|c|c|c|}
\hline Level of schoolinga & \multicolumn{2}{|c|}{$\begin{array}{l}\text { Public Sector } \\
(n=198)\end{array}$} & \multicolumn{2}{|c|}{$\begin{array}{l}\text { Private Sector } \\
\quad(n=188)\end{array}$} & $\chi^{2} \quad(d f)$ & $p$ \\
\hline Elementary school & 74 & 37.4 & 6 & 3.2 & & \\
\hline High school & 108 & 54.5 & 54 & 28.7 & & \\
\hline Higher education/Graduate level & 16 & 8.1 & 128 & 68.1 & & \\
\hline Marital statusb & & & & & $37.676(2)$ & $<0.001$ * \\
\hline Single & 69 & 34.8 & 17 & 9.0 & & \\
\hline Married/Lives with the parter & 126 & 63.6 & 169 & 89.9 & & \\
\hline Divorced/widow & 3 & 1.6 & 2 & 1.1 & & \\
\hline Number of children & & & & & $81.185(1)$ & $<0.001$ * \\
\hline Primigravida & 61 & 30.8 & 144 & 76.6 & & \\
\hline Multigravida & 137 & 69.2 & 44 & 23.4 & & \\
\hline Relationship with the baby's father & & & & & $18.769(1)$ & $<0.001$ * \\
\hline Good & 174 & 87.9 & 186 & 98.9 & & \\
\hline Poor & 24 & 12.1 & 2 & 1.1 & & \\
\hline Family supportc & & & & & - & - \\
\hline Yes & 184 & 92.9 & 188 & 100.0 & & \\
\hline No & 14 & 7.1 & 0 & - & & \\
\hline Pregnancy planning & & & & & $4.698(1)$ & $<0.001$ * \\
\hline Yes & 75 & 37.9 & 137 & 72.9 & & \\
\hline No & 123 & 62.1 & 51 & 27.1 & & \\
\hline Possibility of abortion & & & & & $6.957(1)$ & $0.008^{*}$ \\
\hline Yes & 16 & 8.1 & 4 & 2.1 & & \\
\hline No & 182 & 91.9 & 184 & 97.9 & & \\
\hline Socioeconomic leveld & & & & & $139.00(3)$ & $<0.001$ * \\
\hline A & 1 & 0.5 & 17 & 9.0 & & \\
\hline B & 40 & 20.2 & 133 & 70.7 & & \\
\hline c & 129 & 65.2 & 36 & 19.2 & & \\
\hline $\mathrm{D} / \mathrm{E}$ & 28 & 14.1 & 2 & 1.1 & & \\
\hline
\end{tabular}

$\chi^{2}=$ Chi-square test; $d f=$ degrees of freedom; $a=$ difference found among all the categories; $b=$ difference between the categories single and married/lives with a partner; $c=$ performing the test was not possible because of the rule that none of the cells can be equal 0 ; $d=$ difference between $B$ and $C$. ${ }^{*} p<0.05$. 
between groups through the chi-square test.

These results indicate that there was a difference between all the variables studied in the different health sectors. Regarding level of schooling, most of pregnant women in the private sector had completed undergraduate or graduate studies, whereas the women of the public sector had completed only elementary or high school. Concerning marital status, a higher number of single mothers in the public sector was observed. Furthermore, among the participants of this sector, there was a higher percentage of multigravidas, who classified the relationship with the fathers of their babies as poor, who had not planned the pregnancy and who had considered the possibility of abortion. Regarding socioeconomic level, class B presented a higher number of participants in the private sector while class $\mathrm{C}$ presented the same for the public sector. It was not possible to compare the variable "family support" because of the lack of pregnant women in the private sector under these conditions.

The descriptive data (average and standard deviation) of the anthropometric and psychological variables that were studied, as well as the results of the comparison between both sectors, are exposed in Table 2. With the exception of the subscales of the BAQ "Lower body fatness perception" and "Strength and fitness," statistical differences were identified in all the variables that were analyzed; in the public sector, these conditions were more troubled. Additionally, the effect size varied between small and medium (Cohen's D).

Table 3 below demonstrates the association between the investigated variables. It is important to mention that the values above the diagonal line of the table refer to patients in the public sector, and the ones below it represent the pregnant women of the private sector. Regarding the results of the BAQ, all the variables were significantly correlated for both sectors.

Table 4 presents the results of the regression analysis. For both sectors, the EAT-26 and the RSS were predictors of the BAQ score, varying the intensity of the moderation. Even though the remaining investigated variables presented a correlation with the BAQ in both groups, the BDI and the STAI-trait and state did not add any predictive value in the regression model. As a result they were excluded at the end of the model. The size effects identified varied from small to large.

Table 2

Descriptive analysis and comparison between the anthropometric and psychological variables of pregnant women of the public and the private sectors.

\begin{tabular}{|c|c|c|c|c|c|}
\hline \multirow[t]{2}{*}{ Statistics } & \multirow{2}{*}{$\begin{array}{c}\text { Public Sector } \\
\bar{X} \pm S D\end{array}$} & \multirow{2}{*}{$\begin{array}{c}\text { Private Sector } \\
\overline{\mathrm{X}} \pm \text { SD }\end{array}$} & \multirow[t]{2}{*}{$T$} & \multirow[t]{2}{*}{$p$} & \multirow[t]{2}{*}{ D-Cohen } \\
\hline & & & & & \\
\hline Age (years) & $28.10 \pm 6.67$ & $30.61 \pm 5.01$ & -4.193 & $<0.001 *$ & 0.42 \\
\hline BMI $\left(\mathrm{kg} / \mathrm{m}^{2}\right)$ & $28.32 \pm 6.60$ & $25.93 \pm 6.70$ & 3.532 & $<0.001 *$ & 0.36 \\
\hline Total BAQ & $125,15 \pm 17.28$ & $117.42 \pm 16.45$ & 4.497 & $<0.001 *$ & 0.46 \\
\hline Physical attractiveness & $16.94 \pm 3.04$ & $17.90 \pm 2.46$ & -3.396 & $0,001 *$ & 0.35 \\
\hline Disparagement & $15.75 \pm 4.70$ & $12.79 \pm 3.69$ & 6.914 & $<0.001 *$ & 0.70 \\
\hline Total fat & $31.19 \pm 10.25$ & $34.83 \pm 10.00$ & 4.229 & $<0.001 *$ & 0.36 \\
\hline Body salience & $21.23 \pm 4.45$ & $20.35 \pm 3.88$ & 2.070 & $0,039 *$ & 0.21 \\
\hline Lower body fatness perception & $12.03 \pm 2.87$ & $12.02 \pm 2.86$ & 0.032 & 0,975 & 0.01 \\
\hline Strength and fitness & $17.94 \pm 3,18$ & $18.03 \pm 3.14$ & -0.271 & 0,787 & 0.03 \\
\hline EAT-26 & $15.17 \pm 10.50$ & $12.39 \pm 7.77$ & 7.003 & $<0.001 *$ & 0.30 \\
\hline BDI & $12.89 \pm 10.67$ & $7.90 \pm 5.32$ & 5.857 & $<0.001 * *$ & 0.60 \\
\hline RSS & $4,43 \pm 3.48$ & $7.06 \pm 3.84$ & 4.117 & $<0.001 *$ & 0.72 \\
\hline STAI-trait & $15.82 \pm 3.51$ & $14.46 \pm 2.97$ & 7.440 & $<0.001 *$ & 0.42 \\
\hline STAI-state & $17.69 \pm 2.96$ & $15.42 \pm 3.04$ & 2.959 & $0.003 *$ & 0.76 \\
\hline
\end{tabular}

$\mathrm{SD}=$ Standard Deviation; $\mathrm{BMI}=$ Body Mass Index; $\mathrm{BAQ}=$ Body Attitudes Questionnaire; EAT-26= Eating Attitudes Test-26; $\mathrm{BDI}=$ Beck Depression Inventory; RSS= Rosenberg Self-Esteem Scale; STAI= Brazilian State-Trait Anxiety Inventory.

* significant for $p<0.05$. 
Table 3

\begin{tabular}{|c|c|c|c|c|c|c|c|}
\hline Variables & 1 & 2 & 3 & 4 & 5 & 6 & 7 \\
\hline 1. Total BAQ & - & $0.337^{*}$ & $0.434 *$ & $0.363^{*}$ & $0.406^{*}$ & $0.147^{*}$ & $0.302 *$ \\
\hline 2. BMI $\left(\mathrm{kg} / \mathrm{m}^{2}\right)$ & $0.286^{*}$ & - & 0.106 & 0.072 & 0.105 & $0.158^{*}$ & -0.002 \\
\hline 3. EAT-26 & $0.510 *$ & 0.123 & - & 0.200 * & 0.103 & 0.110 & 0.234 * \\
\hline 4. $\mathrm{BDI}$ & $0.359 *$ & 0.129 & 0.320 * & - & $0.535^{*}$ & 0.271 * & $0.442 *$ \\
\hline 5. RSS & $0.365^{*}$ & 0.029 & 0.171 * & 0.491 * & - & $0.245^{*}$ & $0.344 *$ \\
\hline 6. STAI-trait & $0.270 *$ & $0.165^{*}$ & $0.344^{*}$ & 0.503 & $0.234^{*}$ & - & 0.359 * \\
\hline 7. STAI-state & $0.256^{*}$ & $0.149 *$ & 0.320 * & 0.481 * & $0.303 *$ & $0.542 *$ & - \\
\hline
\end{tabular}

$\mathrm{BAQ}=$ Body Attitudes Questionnaire;BMI= Body Mass Index; EAT-26=Eating Attitudes Test -26 ; BDI=Beck Depression Inventory; RSS=Rosenberg Self-Esteem Scale; STAl=Brazilian State-Trait Anxiety Inventory; ${ }^{*} p<0.05$.

Table 4

Linear regression analyses (forward selection) using the BAQ score as the criteria variable for the public and private sectors.

\begin{tabular}{|c|c|c|c|c|c|c|}
\hline & Block & $\mathbf{R}^{2}$ & $\mathrm{R}^{2}$ adjusted & $F$ & $p$ & F2-Cohen \\
\hline Public Sector & & & & & & 0.51 \\
\hline EAT-26 & 1 & 0.191 & 0.187 & 45.661 & $<0.001^{*}$ & \\
\hline RSS & 2 & 0.343 & 0.336 & 50.046 & $<0.001 *$ & \\
\hline Private Sector & & & & & & 0.48 \\
\hline EAT-26 & 1 & 0.247 & 0.243 & 59.115 & $<0.001 *$ & \\
\hline RSS & 2 & 0.331 & 0.324 & 44.357 & $<0.001 *$ & \\
\hline
\end{tabular}

BAQ=Body Attitudes Questionnaire; EAT-26=Eating Attitudes Test - 26; RSS=Rosenberg Self-Esteem Scale; ${ }^{*} p<0.05$.

\section{Discussion}

The first objective of this study was to compare the sociodemographic, anthropometric and psychological factors of pregnant women receiving care in the private and public health sectors. It was postulated that the groups would differ regarding the aforementioned variables. The results confirmed the initial hypothesis, which reinforces the importance of fostering the preservation and development of public policies that acknowledge biopsychosocial aspects in order to offer full support to pregnant women during pregnancy.

The sociodemographic data indicated that the pregnant women receiving care from the public sector were mostly single and multigravidas: they classified their relationship with the fathers of their babies as "poor;" they had not planned the pregnancy; and they thought about having an abortion. Furthermore, these women also presented less schooling and lower socioeconomic levels when compared to those receiving care from the private health sector. Therefore, the participants of the public sector presented more strained social structures. According to the Ministry of Health, 12 low schooling levels and unfavorable environmental conditions are considered signs that may lead pregnant women to a high-risk pregnancy. Moreover, external and internal structures may impact on the mental health of these women.2,8 Consequently, it is important to pay attention to the pregnant women of the public sector in order to prevent emotional disturbances during this period of their lives.

Regarding the anthropometric variables, a significant difference was observed regarding the age and BMI of pregnant women in both evaluated groups. The patients of the private sector were older and presented a lower BMI when compared to those of the public sector. The studies of Cesar et al. ${ }^{16}$ and Seabra et al. 27 confirm these facts, since the former also verified that pregnant women receiving care in the public sector had an earlier maternal age; and the latter identified a lower BMI of those who were 
receiving care in the private sector. It is possible that women with a higher purchasing power give priority professional endeavors, choosing to plan and postpone their pregnancies for a later age. Regarding the BMI, it is possible that the pregnant women receiving care from the public sector do not pay attention to the importance of weight-gain control during pregnancy. Furthermore, both late pregnancy and overweight/obesity in this period of time are considered risk factors, and as a result may present a higher possibility of complications during pregnancy. 12

When it comes to the comparisons of the BAQ and its subscales, pregnant women of the public sector presented more negative body image (total BAQ), less feeling of "physical attractiveness" and higher scores for "disparagement" and "feeling body salience." It is possible to affirm that the higher BMI values that were identified in the pregnant women of this sector have contributed to this fact. The scientific literature shows in the general population 4 and also in pregnant women 1,2,6 that the higher the BMI, the higher the negative feelings toward one's own body. As a result, a high-quality clinical follow up must be prioritized, especially concerning the body image.

Furthermore, it was verified that the pregnant women receiving care in the public sector are more likely to adopt inappropriate eating attitudes and present depressive symptoms, low self-esteem and higher levels of trait and state anxiety. The comparison of these results with international studies is not advised because health systems differ. In the Brazilian context, only investigations that take into account patients of the public sector were found. Hedrich et al. ${ }^{28}$ verified that women receiving care in the local clinic of their cities presented mostly inappropriate dietary intakes. Thiengo et al.29 demonstrated that depressive symptoms during pregnancy were associated with high-risk behaviors like smoking. Additionally, Dias et al. ${ }^{30}$ pointed out that the low self-esteem of women receiving health care from the public sector was related to the perception of risk for the baby's health and to the number of pregnancies. Lastly, Araújo et al. ${ }^{11}$ verified that anxiety was significantly present in the pregnant women evaluated. Consequently, more research that evaluates both health sectors is recommended in order to prevent and/or control the incidence of unwanted maternal-fetal conditions.

As for a second proposition, the aim was to verify the influences of the variables studied in the body attitudes of pregnant women from both health sectors. Initially, it was verified that high BMI, inap- propriate eating attitudes, depressive symptoms, low self-esteem and high anxiety presented a significant association from small to medium intensity with negative body attitudes, in both public and private sectors. A recent investigation carried out by Meireles et al. ${ }^{9}$ also presented similar results. However, the researchers did not take health sectors into consideration. As a consequence, the observed results deserve attention, since the expression of one or more factors may generate negative changes in the remaining factors. 3,9 This fact can impact on the mother's and baby's health in both public and private sectors.

The results of the regression analyses pointed out that eating attitudes and self-esteem were predictors of the body attitudes of pregnant women in both groups. Previous studies had already demonstrated the influence of eating attitudes 8,9 and self-esteem 6 in the body image of pregnant women. Nonetheless, in this study, the percentage that explains these variables on the BAQ was different according to the sector. In the public sector, the eating attitudes contributed to $18.7 \%$ of these variables, whereas in the private sector $24.3 \%$ did. After adding selfesteem into the models, the explanatory percentage was $33.6 \%$ and $32.4 \%$ in the public and private sector, respectively. Therefore, it is possible to affirm that, in the private sector, the contribution of the EAT-26 was greater than in the public sector. It is possible that pregnant women with higher purchasing power pay more attention to eating issues.

Despite the contributions of this investigation to the knowledge in the field, this research presents limitations that need to be mentioned. First, it is difficult to establish cause-and-effect relations in the cross-sectional studies. However, this methodology has been used in other investigations of pregnant women. ${ }^{7-10,13,16}$ A second limitation is the use of tools that are not specific for this population. On the other hand, they demonstrated acceptable internal consistency for this sample. ${ }^{25}$

It would be interesting if further studies evaluated longitudinally the body image of pregnant women receiving health in the public and private health sectors in order to show how they behave in each trimester of pregnancy. It is important to mention that the public sector lacks more attention regarding the evaluations, especially regarding body image, which had not been investigated so far between the sectors. It is also suggested the creation and validation of specific instruments that evaluate the body image of pregnant women in order to get to know their concerns toward their bodies. 
It was concluded that the sociodemographic, anthropometric, and psychological factors were more worrying in pregnant women receiving care in the public sector when compared to those of the private sector. Furthermore, eating attitudes and selfesteem directly influenced the body attitudes of the

\section{References}

1. Meireles JFF, Neves CM, Carvalho PHB, Ferreira MEC. Insatisfação corporal em gestantes: uma revisão integrativa da literatura. Ciênc Saúde Colet. 2015; 20 (7): 2091-103.

2. Skouteris H. Body Image Issues in Obstetrics and Gynecology. In: Cash TF, Smolak L. (Eds.). Body image: A handbook of science, practice, and prevention. 2nd ed. New York: The Guilford Press; 2011. p. 56-64.

3. Watson B, Fuller-Tyszkiewicz M, Broadbent J, Skouteris $\mathrm{H}$. The meaning of body image experiences during the perinatal period: a systematic review of the qualitative literature. Body Image. 2015; 14: 102-13

4. Laus MF, Kakeshita IS, Costa TMB, Ferreira MEC, Fortes LS, Almeida SS. Body image in Brazil: recent advances in the state of knowledge and methodological issues. Rev Saúde Pública. 2014; 48 (2): 331-46.

5. Thompson JK, Heinberg LJ, Altabe MN, Tantleff-Dunn S Exacting beauty: Theory, assessment and treatment of body image disturbance. Washington, DC: American Psychological Association; 1999.

6. Kamysheva E, Skouteris H, Wertheim EH, Paxton SJ, Milgrom J. Examination of a multi-factorial model of bodyrelated experiences during pregnancy: The relationships among physical symptoms, sleep quality, depression, selfesteem, and negative body attitudes. Body Image. 2008; 5 (2): $152-63$.

7. Meireles JFF, Neves CM, de Carvalho PHB, Ferreira MEC Imagem corporal de gestantes: associação com variáveis sociodemográficas, antropométricas e obstétricas. Rev Bras Ginecol Obstet. 2015; 37 (7): 319-24.

8. Meireles JFF, Neves CM, de Carvalho PHB, Ferreira MEC. Imagem corporal de gestantes: um estudo longitudinal. J Bras Psiquiatr. 2016; 65 (3): 223-30.

9. Meireles JFF, Neves CM, de Carvalho PHB, Ferreira MEC. Imagem corporal, atitudes alimentares, sintomas depressivos, autoestima e ansiedade em gestantes de Juiz de Fora Minas Gerais, Brasil Ciênc Saúde Colet. 2017; 22 (2): 437 45 .

10. Sweeney AC, Fingerhut R. Examining relationships between body dissatisfaction, maladaptive perfectionism, and postpartum depression symptoms. J Obstet Gynecol Neonatal Nurs. 2013; 42 (5): 551-61.

11. Araújo DMR, Pacheco AHDRN, Pimenta AM, Kac G Prevalência e fatores associados a sintomas de ansiedade em uma coorte de gestantes atendidas em um centro de saúde do município do Rio de Janeiro. Rev Bras Saúde Mater Infant. 2008; 8 (3): 333-40

12. Brasil. Ministério da Saúde. Manual Técnico: Gestação de alto risco: atenção qualificada e humanizada. Brasília, DF 2012. pregnant women in both groups. Since the consequences may be harmful for the mother's and child's health, it is essential that professionals be aware of the necessity of full support to pregnant women during the prenatal period.

13. Skouteris H, Carr R, Wertheim EH, Paxton SJ, Duncombe D. A prospective study of factors that lead to body dissatisfaction during pregnancy. Body Image. 2005; 2 (4): 347-61.

14. Girardi SN, Stralen ACS, Lauar TV, Cella JN, Araújo JF, Pierantoni CR, Carvalho CL. Escopos de prática na Atenção Primária: médicos e enfermeiros em cinco regiões de saúde do Brasil. Rev Bras Saúde Mater Infant. 2017; 17 (Suppl 1): S171-S84.

15. Cesar JA, Mano PS, Carlotto K, Gonzalez-Chica DA, Mendoza-Sassi RA. Público versus privado: avaliando a assistência à gestação e ao parto no extremo sul do Brasil. Rev Bras Saúde Matern Infant. 2011; 11 (3): 257-63.

16. Cesar JA, Sutil AT, dos Santos GB, Cunha CF, MendozaSassi RA. Assistência pré-natal nos serviços públicos e privados de saúde: estudo transversal de base populacional em Rio Grande, Rio Grande do Sul, Brasil. Cad Saúde Pública. 2012; 28 (11): 2106-114.

17. Nascimento LFC. Perfil de gestantes atendidas no período pré-natal e perinatal: estudo comparativo entre os setores público e privado em Guaratinguetá, São Paulo. Rev Bras Saúde Matern Infant. 2003; 3 (2): 187-94

18. Thomas JR, Nelson, JK, Silverman SJ. Métodos de pesquisa em atividade física. São Paulo: Artmed; 2012.

19. Scagliusi FB, Polacow VO, Cordás TA, Coelho D, Alvarenga M, Philippi ST, Lancha AH Jr. Psychometric testing and applications of the Body Attitudes Questionnaire translated into Portuguese. Percept Mot Skills. 2005; 101 (1): 25-41.

20. Nunes MA, Camey S, Olinto MTA, Mari JJ. The validity and 4-year test-retest reliability of the Brazilian version of the Eating Attitudes Test-26. Braz J Med Biol Res. 2005; 38 (11): 1655-62.

21. Gorenstein C, Andrade L. Validation of a Portuguese version of Beck Depression Inventory and the State-Trait Anxiety Inventory in Brazilian subjects. Braz J Med Biol Res. 1998; 29 (4): 453-7.

22. Dini GM, Quaresma MR, Ferreira LM. Adaptação cultural e validação da versão brasileira da Escala de Auto-estima de Rosenberg. Rev Soc Bras Cir Plást. 2004; 19 (1): 41-52.

23. Fioravanti-Bastos ACM, Cheniaux E, Landeira-Fernandez J. Development and validation of a short-form version of the Brazilian State-trait Anxiety Inventory. Psicol Reflex Crit. 2011; 24 (3): 485-94.

24. Associação Brasileira de Empresas de Pesquisa [Internet]. Critério de Classificação Econômica Brasil. [acesso em 7 dez 2014]. Disponível em: http://www.abep.org/criteriobrasil.

25. Hair Júnior JF, Black WC, Babin BJ, Anderson RE, Tatham RL. Análise multivariada de dados. 6a Ed. São Paulo: Bookman; 2009. 
26. Cohen J. A power primer. Psychol Bull. 1992; 112 (1): 155-

27. Seabra G, Padilha PC, de Queiroz JA, Saunders C. Sopreso e obesidade pré-gestacionais: prevalência e desfechos associados à gestação. Rev Bras Ginecol Obstet. 2011; 33 (11): 348-53.

28. Hedrich A, Novello D, Ruviaro L, Alves J, Quintiliano DA. Perfil alimentar, estado nutricional, de saúde e condições sócio-econômicas de gestantes assistidas por centros de saúde do município de Guarapuava-PR. Rev Salus. 2007; 1 (2): $139-46$
29. Thiengo DL, Santos JFC, Fonseca DL, Abelha L, Lovisi GM. Depressão durante a gestação: um estudo sobre a associação entre fatores de risco e de apoio social entre gestantes. Cad Saúde Colet. 2012; 20 (4): 416-26.

30. Dias MS, da Silva RA, Souza LDM, Lima RC, Pinheiro RT, Moraes IGS. Autoestima e fatores associados em gestantes da cidade de Pelotas, Rio Grande do Sul, Brasil. Cad Saúde Pública. 2008; 12: 2787-97.

Received on March 29, 2018

Final version presented on November 1, 2018

Approved on January 22, 2019 